\title{
Crocidura shantungensis, a New Species for Mongolia and Buryatia
}

\author{
A. A. Bannikova, B. I. Sheftel, V. S. Lebedev, \\ D. Yu. Aleksandrov, and M. Muehlenberg \\ Presented by Academician Yu.I. Chernov May 27, 2008
}

Received May 27, 2008

DOI: $10.1134 / \mathrm{S} 0012496609010207$

The Manchurian white-toothed shrew Crocidura shantungensis Miller, 1901 has been identified as a separate species from a polytypic group of 40-chromosome shrews of the species group C. suaveolens Pallas, 1811; it belongs to the Far Eastern and Chinese populations of $C$. suaveolens. The authors of the reports [1] and [2] were the first to make a guess that small whitetoothed shrews of the group $C$. suaveolens from the Chinese provinces Shandong, Sichuan, Shaanxi, and Zhejiang were darker and more long-tailed than those populating Europen and Central and Middle Asian regions; they were also supposed to belong to a separate species, $C$. shantungensis. Later on, the authors of [3] examined the South China whitetoothed shrews and found that $C$. suaveolens and C. shantungensis differed in several craniometric traits. Sequencing of the mitochondrial cytochrome $\mathrm{b}$ gene confirmed the molecular genetic apartness of C. shantungensis [4]. Its divergence with respect to $c y t b$ from the remaining members of the suaveolens group was as high as $13 \%$, which corresponds to $\sim 1.2-1.3 \mathrm{Myr}$ ago [5].

At present, this species is assumed to populate an area including Southern Primoriye, Korea, eastern and northeastern China and adjacent islands (Popov, Putyatin, Tsushima, Taiwan, Ullyndo, Cheju) [3, 6-8] (Fig. 1). In China, the area boundaries are assumed to follow the border of the mixed broad-leaved forest zone, which suggests that $C$. shantungensis is more hydrophilous than the small white-toothed shrew. Single individuals of $C$. shantungensis and $C$. suaveolens

\footnotetext{
Moscow State University, Moscow, 119991 Russia Severtsov Institute of Ecology and Evolution, Russian Academy of Sciences, Leninskii pr. 33, Moscow, 119071 Russia

Georg-August University of Goettingen, Von-Siebold-Str. 2, D-37075 Goettingen, Germany
}

are difficult to diagnose on the basis of morphological traits. In fact, the diagnostic features used in [3] are mostly dimensional ones (C. shantungensis is substantially smaller). Because of this, the eastern boundary of the small shrew distribution is not clearly defined, and the relationships between the areas of the two species remain still questionable.

In the summer of 2007, during an expedition to Mongolia and Buryatia, we procured six white-toothed C. suaveolens s. l. on the western mountainside of the Khingan range, in the Nutryk River floodplain $\left(46^{\circ} 59^{\prime} 03^{\prime \prime} \mathrm{N}, 119^{\circ} 36^{\prime} 43^{\prime \prime} \mathrm{E}\right)$; two individuals were caught in the middle of the Chikoi River floodplain (the left bank of the Chikoi River, 50 $52^{\prime} 30^{\prime \prime} \mathrm{N}, 106^{\circ} 38^{\prime} 30^{\prime \prime} \mathrm{E}$ ). In Mongolia (Khingan), the animals were caught at a distance of 10-30 $\mathrm{m}$ from water in the floodplain herbgrass tall-grass wet meadows alternating with riverbank willow groves. In Buryatia, white-toothed shrews were caught in a floodplain apple tree-willow-elm forest with a heavy shrub layer of bird-cherry tree, hawthorn, thorny dog-rose, and Siberian dogwood with a thick herb layer under the vertical rocky eastern-southern mountain cropping at a distance of $20 \mathrm{~m}$ from water.

To perform genetic typing of the white-toothed shrew, sequencing the entire mitochondrial cytochrome b gene (cyt $b, 1140 \mathrm{bp}$ ) was used. The data obtained were compared with those on $C$. suaveolens from the eastern part of the area and $C$. shantungensis from Primoriye (Lazo Reserve) and with GenBank data. Phylogenetic analysis used the methods of maximum likelihood (ML), neighbor joining (NJ), and maximum parsimony (MP) implemented in the $P A U P^{*}$ software version $4.0 \mathrm{~b} 10$.

Morphological parameters of the white-toothed shrew from eastern Mongolia and Buryatia were determined by measuring the sizes of the body and skull, and by defining the sex, age, and generative state of the animals (table). On the basis of these traits, diagnosing C. shantungensis was possible at the highest probabil- 


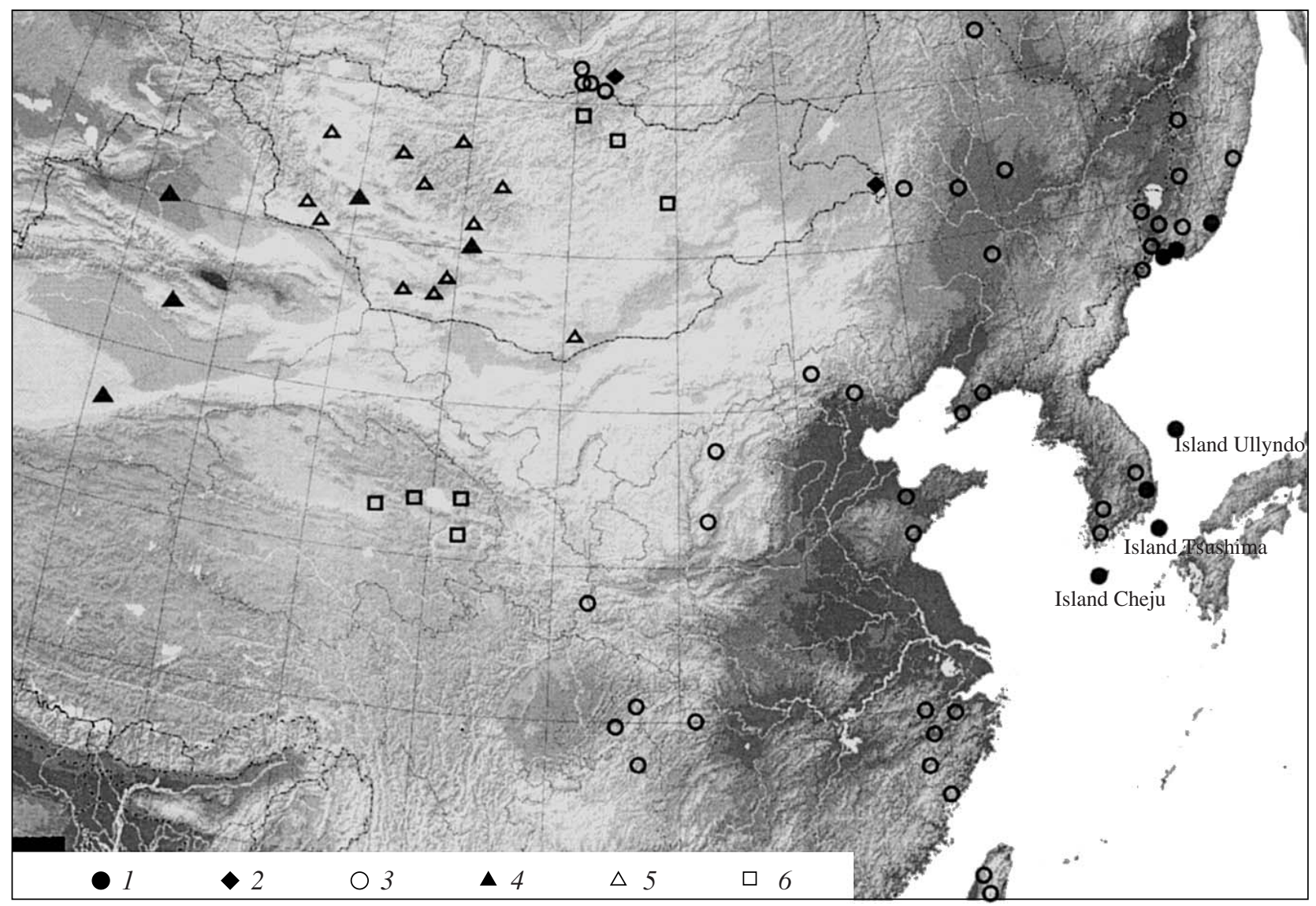

Fig. 1. Distribution of the Manchurian shrew C. shantungensis. 1, localities from where the genetically defined $C$. shantungensis are known; 2, genetically defined new findings of this species; 3, localities presumably inhabited by $C$. shantungensis (including the catching places where the specimens have been identified on the basis of morphometric data); 4 , localities from where the genetically defined $C$. suaveolens are known; 5, C. suaveolens habitats (according to the morphological data); 6 , the catching places of uncertain species affiliation. Shrew localities from China are taken from [3]; the localities from Korea, Xinjiang, and from southern Mongolia (Sharga) are taken from [4]; the localities from Buryatia and Far East of Russia are taken from [6] and [8], respectively; those from southern Mongolia are taken from [7] and from the materials of Zoological Museum, Moscow State University.

ity [3]; however, the values obtained also fell into the range of those characteristic of the small shrew.

Five haplotypes were identified by sequencing the $c y t b$ gene of white-toothed shrews from Khingan, Buryatia, and Lazo Reserve. These were two out of six haplotypes of Khingan animals, two out of three haplotypes of Lazo Reserve ones, and the same haplotype was characteristic of both Buryatian animals (EU742583-EU742594).

Both Khingan and Lazo Reserve haplotypes belonged to the group of $C$. shantungensis haplotypes available at the GenBank and characteristic of Primoriye; Taiwan; islands Putyatin, Popov, and Ullyndo; and South Korea. The Buryatian haplotype was peculiar. According to the phylogenetic analysis (NJ, ML, and MP) of all original data (Fig. 2), on the phylogenetic tree, both Khingan and Buryatian white-toothed shrews constituted an individual group that also included white-toothed shrews from Primoriye (their $c y t b$ gene has been sequenced in this study) and those from Taiwan and islands Putyatin, Popov, Ullyndo, Tsushima, and Cheju (their cyt $b$ gene sequences are available at GenBank as $C$. shantungensis). This clade was $100 \%$ supported in all analyses (MP/ML/NJ). Between $C$. shantungensis and $C$. suaveolens s. str., the genetic distance (p-distance) was 13\%. Three groups of $C$. shantungensis are distinguishable: (1) the haplotypes found in Khingan, Southern Primoriye (Lazo Reserve), Taiwan, and islands Putyatin, Popov, and Ullyndo; (2) the Buryatian haplotype that differed from those listed above by eleven substitutions on average; on the phylogenetic tree, this haplotype formed an independent sister branch; (3) the haplogroup typical of islands Tsushima and Cheju (the Korean Strait). This last group was the most isolated; it differed by 17 or 18 substitutions and was the basic one with respect to the first two haplogroups. The genetic dis- 


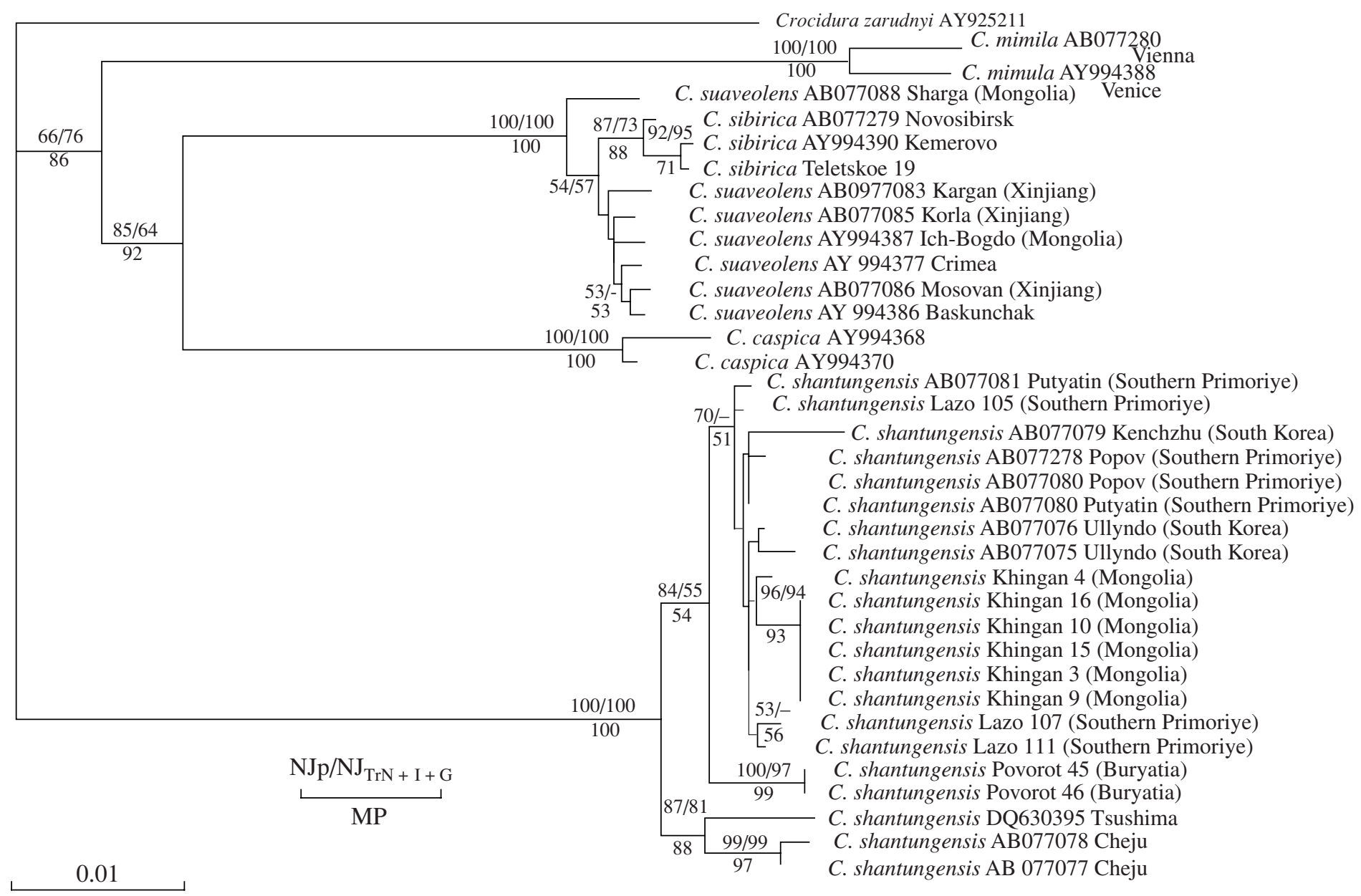

Fig. 2. The NJ tree of phylogenetic relationships between $C$. shantungensis and animals from $C$. suaveolens $\mathrm{s}$. 1. group (constructed on the basis of $1140 \mathrm{bp}$ of the mitochondrial gene $c y t b$ ). Clade supports in bootstrap analysis (1000 replicas) determined on the basis of the $p$-distances and using the $\operatorname{TrN}+\mathrm{I}+\Gamma$ model are shown above the branches $\left(\mathrm{NJ}_{\mathrm{p}} / \mathrm{NJ} \operatorname{TrN}+\mathrm{I}+\Gamma\right)$. Below the branches are the bootstrap supports in MP analysis.

tances between three branches of $C$. shantungensis were 1.0 and $1.5 \%$.

Thus, $c y t b$ sequencing has demonstrated that whitetoothed shrews from Khingan and Transbaikalia belong to the species $C$. shantungensis, rather then $C$. suaveolens, as it was previously assumed. In Mongolia and Buryatia, this species has been found for the first time. The Buryatian findings extend the area of the Manchurian white-toothed shrew far westwards and suggest that it is most likely to be adjacent to the area of the small white-toothed shrew. The Mongolian findings demonstrate that this species is encountered not only on the eastern, but also on the western macroslope of the Great Khingan Range. Our results also suggest that, in the past, the Manchurian white-toothed shrew populated a vaster area, probably, because of the more extended and continuous zone of broadleaved forests.
In Pleistocene, the species refugium could be in the Far East (Korea or Manchuria). The presentday populations of the Korea Strait islands have originated from another refugium, which existed simultaneously with the first one. Some time afterwards, the white-toothed shrew from the first refugium spread westwards and soon reached Buryatia. Subsequent discontinuity of the area (if it really exists and Buryatian population is indeed an isolated one) occurred because of land aridization and reduction of the broad-leaved forest area. The finding of $C$. shantungensis in southern Buryatia is so unexpected that it gives thought to the status of small white-toothed shrews from central Mongolia (Eastern Khangai, the middle reaches of the Orhon River, and the upper course of the Kerulen River, Hentei), which have never been analyzed genetically. 
The body and skull sizes (mm) of shrews from the western side of the Khingan Range and the left bank of the Chikoi River

\begin{tabular}{|c|c|c|c|c|c|c|c|c|c|}
\hline $\begin{array}{l}\text { ZMMU } \\
\text { code }\end{array}$ & $\begin{array}{l}\text { Locality, sex, } \\
\text { age }\end{array}$ & BL & TL & FL & CBL & PL & SW & RW & IOL \\
\hline $63 / 07 \_3$ & $\begin{array}{l}\text { Khingan, m, } \\
\text { immature }\end{array}$ & 57 & 27 & 10 & 16.0 & 7.1 & 7.5 & 5.0 & 3.5 \\
\hline 63/07_9 & $\begin{array}{l}\text { Khingan, m, } \\
\text { immature }\end{array}$ & 61 & 28 & 10 & 16.7 & 7.3 & 7.7 & 5.3 & 3.7 \\
\hline 63/07_15 & $\begin{array}{l}\text { Khingan, m, } \\
\text { mature }\end{array}$ & 60 & 27 & 10.5 & 16.9 & 7.5 & 7.8 & 5.2 & 3.7 \\
\hline $51 / 07 \_45$ & $\begin{array}{l}\text { Khingan, f, } \\
\text { mature }\end{array}$ & 60 & 27 & 10 & 16.0 & 7.2 & 7.7 & 5.1 & 3.6 \\
\hline 51/07_46 & $\begin{array}{l}\text { Khingan, } f, \\
\text { embryo } 2+3\end{array}$ & 60 & 28 & 10 & 16.3 & 7.4 & 8.0 & 5.3 & 3.6 \\
\hline & & \multicolumn{8}{|c|}{ C. shantungensis $(n=33)$} \\
\hline \multirow{4}{*}{\multicolumn{2}{|c|}{$\begin{array}{l}\text { Average values } \\
\text { and variation range } \\
\text { according to Jiang } \\
\text { and Hoffman (2001) }\end{array}$}} & $\begin{array}{l}60.9 \pm 5.00 \\
51.0-71.0\end{array}$ & $\begin{array}{c}38.1 \pm 3.73 \\
28-45\end{array}$ & & $\begin{array}{l}16.82 \pm 0.39 \\
16.16-17.52\end{array}$ & $\begin{array}{c}7.48 \pm 0.15 \\
7.06-7.79\end{array}$ & $\begin{array}{c}7.64 \pm 0.27 \\
6.98-8.11\end{array}$ & $\begin{array}{l}5.11 \pm 0.20 \\
4.51-5.42\end{array}$ & $\begin{array}{l}3.86 \pm 0.15 \\
3.48-4.09\end{array}$ \\
\hline & & \multicolumn{8}{|c|}{ C. suaveolens $(=C$. gmelini $)(n=14)$} \\
\hline & & $59.8 \pm 4.37$ & $31.8 \pm 3.47$ & & $17.77 \pm 0.36$ & $8.18 \pm 0.18$ & $8.08 \pm 0.25$ & $5.51 \pm 0.18$ & $4.20 \pm 0.13$ \\
\hline & & $52.0-68.0$ & $25.0-38.0$ & & $17.09-18.29$ & $7.84-8.48$ & $7.40-8.38$ & $5.19-5.81$ & $3.96-4.42$ \\
\hline
\end{tabular}

Note: BL, body length; TL, tail length; FL, foot length; CBL, condylobasal skull length; PL, palatine length; SW, skull width; RW, rostrum width; ITRL, intermediate tooth row length; IOL, interorbital length; ZMMU, Zoological Museum of Moscow University; m, males; f, females.

\section{ACKNOWLEDGMENTS}

This study was supported by the Russian Foundation for Basic Research (project no. 08-04-00029).

\section{REFERENCES}

1. Hoffmann, R.S., in Contributions in Mammalogy: A Memorial Volume Honoring Dr. J. Knox, Lubbok: Texas Tech. Univ., 1996, pp. 155-168.

2. Motokawa, M., in Recent Advances in the Biology of Japanese Insectivora (Proc. Symposium on the Biology of Insectivores in Japan and on the Wildlife Conservation), Shobara: Hiba Soc. Nat. History, 1999, pp. 63-71.

3. Jiang, X.-L. and Hoffmann, R.S., J. Mammal., 2001, vol. 82, no. 4, pp. 1059-1079.
4. Ohdachi, S.D., Masahiro, A.I., Nesterenko, V.A., et al., J. Mammal., 2004, vol. 85, no. 3, pp. 396-403.

5. Bannikova, A.A., Lebedev, V.S., Kramerov, D.A., and Zaitsev, M.V., Mammalia, 2006, vol. 70, no. 2, pp. 106119.

6. Shvetsov, Yu.G., Smirnov, M.N., and Monakhov, G.I., Mlekopitayushchie basseina ozera Baikal (Mammals of the Lake Baikal Basin), Novosibirsk: Nauka, 1984.

7. Sokolov, V.E. and Orlov, V.N., Opredelitel' mlekopitayushchikh Mongol'skoi Narodnoi Respubliki (Index to Mammals of the Mongolian People's Republic), Moscow: Nauka, 1980.

8. Nesterenko, V.A., Nasekomoyadnye yuga Dal'nego Vostoka i ikh soobshchestva (Insectivores of the Southern Far East and Their Communities), Vladivostok: Dal'nauka, 1999. 